\title{
Fixed interval performance as related to instructions and to subjects' verbalizations of the contingency'
}

LOUIS G. LIPPMAN AND MERLE E. MEYER

WESTERN WASHINGTON STATE COLLEGE

Sixteen female Ss eamed a total of 50 reinforcements on a FI 20 sec reinforcement schedule. The reinforcers used were points on a counter. The Ss were instructed that the reinforcement contingency involved either the number of responses, or an interval of time, or Ss were given no information about the schedule. The $S s^{\prime}$ performance was related not only to instructions, but also to Ss' verbalizations of the reinforcement contingency.

The accumulation of points has been shown to be an effective reinforcer for a button pressing operant for humans under a variety of reinforcement contingencies (Kaufman, Baron, \& Kopp, 1966; Welner, 1962, 1964). Of particular interest was the finding that human Ss persistently produced high rates of interreinforcement responding on fixed interval (FT) schedules despite prolonged exposure and practice with FI reinforcement (Weiner, 1962). These response records exhibited no scalloping, but instead closely approximated records obtained under a variable ratio (VR) reinforcement contingency.

Human FI performance may be modified by the introduction of response-cost (Weiner, 1962), and by the manipulation of the S's reinforcement history (Weiner, 1964). Furthermore, human VI performance may be modified by instructions (Kaufman, Baron, \& Kopp, 1966), although instructions have typically been employed or viewed as an alternative to shaping the operant behavior (Ayllon \& Azrin, 1964).

The purpose of the present experiment is to assess Ss' response topographies and their verbalizations of reinforcement contingencies under a FI $20 \mathrm{sec}$ reinforcement schedule, as related to various instructions. Subjects

The Ss were 16 female volunteers from introductory psychology classes. Three Ss were given interval instructions, three ratio, and ten were not instructed. Apparatus

A vertical panel, on which was mounted a four digit counter and two green lights, was fastened to a table in the experimental room. On a horizontal platform, in front of the panel, was the manipulandum, which consisted of a push button requiring a pressure of $1200 \mathrm{~g}$ for closing the electric circuit. In the experimental room, white noise served as an auditory mask for all the associated programming equipment which was housed in an adjoining room. Standard relay equipment was used to program a FI $20 \mathrm{sec}$ reinforcement con- tingency. The S's responses and reinforcements were recorded on counters and on a cumulative recorder. The reinforcers were points on the S's counter. Procedure

The S read a duplicated page of instructions before entering the experimental room. When $S$ indicated that she had read and understood the instructions, $E$ borrowed her watch under the guise of having forgotten his watch, and took $S$ into the experimental room. (At no time did any $S$ voluntarily report suspicion aroused by this procedure.) The S's instruction sheet was available for reference throughout training.

The instructions for all three groups were parallel in construction with the exception of the third paragraph. The first, second, and fourth paragraphs of the instructions were identical for all groups:

"This is an experiment in learning and not a 'psychological test.' We are interested in certain relationships of the learning process which are common to all people, and are not concerned with your personal reactions, intelligence, or personality.

"In the experimental room is a small panel with two lights, a push button, and a counter. Your goal is to accumulate as many points as possible. When you get a point, the lights will flash and the point will be scored on the counter; thus the counter will show the total number of points you accumulate. The way to obtain points is by pushing the button.

"When you press the button, be sure to press it all the way down, and then release it immediately." The third paragraph for the interval-instructed group (I) was as follows:

"After getting a point, you can obtain another by pressing the button after a certain amount of time has elapsed. The amount of time will vary somewhat from point to point."

The third paragraph for the ratio-ir structed group (R) stated:

"After getting a point, you can obtain another by pressing the button a certain number of times. The number of button presses will vary somewhat from point to point."

No additional instructions were included in the noninstructed group (N).

After accumulating 50 points, $E$ removed the instruction sheet and asked $S$ to write an answer to the following question, which was duplicated on the top of a sheet of paper: "Briefly describe, as clearly as 
possible, the condition for getting points in the present experiment."

\section{Results and Discussion}

The results of Groups I and $R$ are presented graphically in Fig. 1 and the data for all three groups are summarized in Table 1 . It can be seen that all Ss in Group I began to scallop early in training. Table 1 shows that these Ss were most saving in responses, but not in total time to earn 50 points. All Ss in Group I verbalized that the interval between reinforcements was fixed, with the estimates of the interval ranging from 30 to $35 \mathrm{sec}$.

Two of the Ss in Group $R$ maintained a high rate of responding throughout training and later verbalized the reinforcement contingency as requiring a varying number of button presses. In their verbal reports, S4 proposed that rapid responding was a requisite for reinforcement, and S5 advanced that the number of responses required for reinforcement increased during training from 14 to 50 per point. It can be seen that both of these Ss earned 50 points most quickly, but at the "expense" of a large number of button presses. On the basis of these Ss' performance, it may be suggested that Weiner's Ss had adopted an effective response strategy with regard to the setting conditions for a vigilance task (Weiner, 1962). Consequently, high and continuous rates of responding may not represent typical FI performance in humans. The third $\mathrm{S}$ showed a marked shift in response rate after approximately 11 reinforcements. Her performance, as well as her verbalization that there were $20 \mathrm{sec}$ between reinforce-

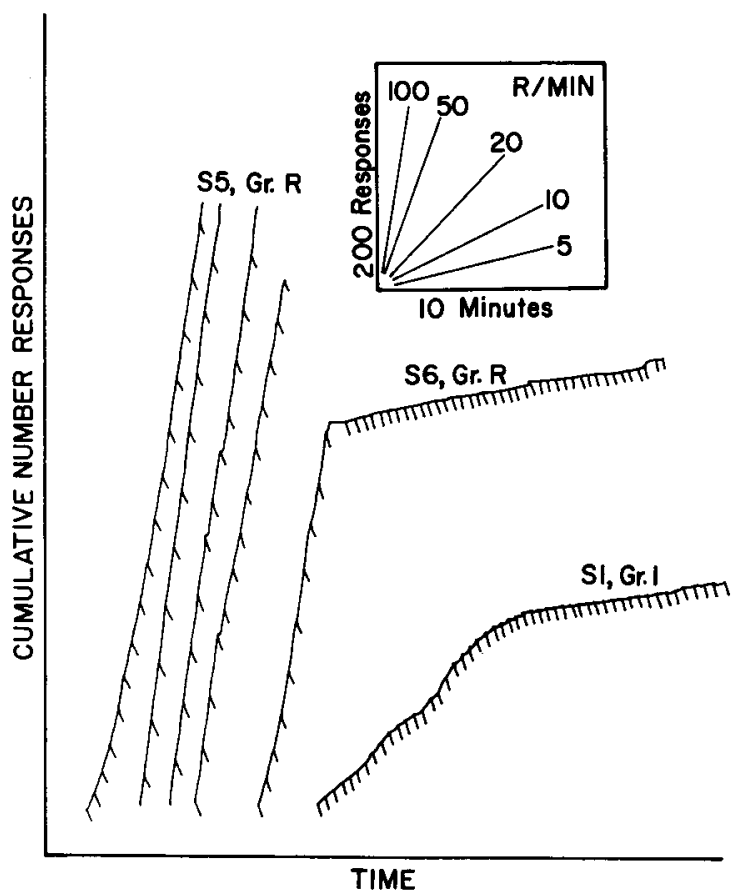

Fig. 1. Cumulative records of $S s$ in groups $I$ and $R$.
Table 1. Summary of all Ss' data

\begin{tabular}{|c|c|c|c|c|c|}
\hline S & V & $\begin{array}{c}\text { Verbalized } \\
\text { (I or R) }\end{array}$ & $\begin{array}{l}\text { Total number } \\
\text { of responses }\end{array}$ & $\begin{array}{l}\text { Total time } \\
\text { required to } \\
\text { obtain } 50 \\
\text { reinforcements }\end{array}$ & $\begin{array}{l}\text { Shifted from } \\
\text { steady re- } \\
\text { ponse-rate to } \\
\text { scalloping }\end{array}$ \\
\hline \multicolumn{6}{|l|}{ Group I } \\
\hline & 1 & 1 & 203 & $18.75 \mathrm{~min}$. & 1. after I SR \\
\hline & 2 & I & 116 & 22.25 & after 3 SR \\
\hline & 3 & $\mathbf{I}$ & 103 & 25.00 & after 3 SR \\
\hline \multicolumn{6}{|l|}{ Group R } \\
\hline & 4 & $\mathbf{R}$ & 3150 & 17.00 & never \\
\hline & 5 & $\mathbf{R}$ & 2127 & 17.00 & never \\
\hline & 6 & I & 405 & 19.33 & after $11 S R$ \\
\hline \multicolumn{6}{|l|}{ Group N } \\
\hline & 7 & $\mathbf{R}$ & 4243 & 16.67 & never \\
\hline & 8 & $\mathbf{R}$ & 3924 & 16.67 & never \\
\hline & 9 & $\mathbf{R}$ & 1855 & 17.33 & never \\
\hline 10 & 0 & I & 164 & 17.00 & ofter 2 SR \\
\hline 11 & 1 & 1 & 274 & 19.17 & ofter $9 \mathrm{SR}$ \\
\hline 12 & 2 & I & 1617 & 18.50 & after 33 SR \\
\hline 13 & 3 & I & 334 & 16.67 & after 13 SR \\
\hline 14 & 4 & I & 316 & 17.33 & after 3 SR \\
\hline 15 & 5 & I & 1832 & 16.75 & ofter 43 SR \\
\hline 16 & 6 & 1 & 1600 & 17.00 & never \\
\hline
\end{tabular}

ments, indicate that she counteracted the instructional set.

Three Ss in Group N verbalized a response-based schedule and estimated that from 60 to 130 responses were required per reinforcement. Their performance records closely approximate the record of S5 in Fig. 1. As with both Ss 4 and 5 in Group $R$, these Ss' mediation of the time interval was incorporated into the measured operant. The remaining seven Ss in Group $N$ verbalized a time-based reinforcement schedule and estimated the interreinforcement interval as ranging from 15 to $30 \mathrm{sec}$. Six of these seven Ss verbalized a temporal contingency and shifted from a high, steady response rate to scalloping. Their records are highly similar to the record of S6 in Group $R$. The seventh S (S16), however, emitted a high, consistent rate of response without any evident shift in rate at any point during training; her record closely approximates the records of all Ss who verbalized a response-based reinforcement contingency.

\section{References}

Ayllon, T., \& Azrin, N. H. Reinforcement and instructions with mental patients. J. exp. Anal. Behav., 1964, 6, 327-331.

Kaufman, A., Baron, A., \& Kopp, Rosemarie E. Some effects of instructions on human operant behavior. Psychon. Monogr. Suppl., 1966,1 , No. 11.

Weiner, H. Some effects of response cost upon human operant behavior. J. exp. Anal. Behav., 1962, 5, 201-208.

Weiner, H. Conditioning history and human fixed-interval performance. J. exp. Anal. Behav., 1964, 7, 383-385.

\section{Note}

1. This research was supported by funds from Western Washington State College. The authors wish to thank $J$. David Leander for his assistance in data collection. 